\title{
Introducción
}

\author{
Charles F. Walker \\ Universidad de California, Davis
}

A la memoria de Enrique Tandeter, nuestro amigo, amigo de los Andes

El tema de este dossier, "Los Andes en el siglo XVIII", trae inmediatamente a la memoria dos cuestiones vinculadas entre sí: las reformas borbónicas y la serie de levantamientos sociales ocurridos durante el período, sobre todo las dos rebeliones más grandes y conocidas, las de Tupac Amaru y Tupac Katari. Estos dos ejes de análisis predominan en la bibliografía, al nivel de monografías, antologías, y resúmenes historiográficos. Sin duda, las reformas impuestas desde Madrid y las rebeliones masivas - que hasta cierto punto fueron una reacción al reformismo- constituyeron cambios y momentos radicales que afectaron o marcaron a las sociedades andinas más allá de la independencia y han despertado el interés de generaciones de historiadores. ${ }^{1}$ Sin embargo, a pesar de este interés, no contamos con análisis satisfactorios de todas las facetas de estos fenómenos y los interrogantes frente a ellos siguen en pie.

Los ensayos aquí publicados presentan nuevas perspectivas sobre el siglo borbónico en los Andes, que si bien se alejan de los parámetros básicos (cronológico, geográfico y metodológico) del enfoque en las reformas y las rebeliones, no los abandonan del todo. Desde esta perspectiva, junto

1 Los trabajos clásicos sobre las reformas incluyen Lynch, John: Spanish Colonial Administration, 1782-1810, University of London Press, London, 1958. Lynch, John: El siglo XVIII. Historia de España, Editorial Crítica, Barcelona, 1991; Fisher, John: Gobierno y sociedad en el Perú colonial: el régimen de las intendencias, 1784-1814, Lima, Pontificia Universidad Católica, 1981. Para un reciente resumen, ver Fisher, John: El Perú borbónico 1750-1824, IEP, 2000, traducción de Javier Flores. Entre las nuevas interpretaciones, ver Guimerá, Agustín, ed.: El reformismo borbónico, CSIC, Alianza Editorial, Madrid, 1996. O’Phelan Godoy, Scarlett: "Historiografía anglosajana sobre las reformas borbónicas en la América española con énfasis en el Perú”, Histórica, XXV-1, 2002, págs. 220 261. Sobre las rebeliones, O'Phelan, Scarlett: Un siglo de rebeliones anticoloniales: Perú y Bolivia 1700-1783, Centro de Estudios Rurales Andinos "Bartolomé de las Casas", Cusco, Perú, 1988. Flores Galindo, Alberto: TúpacAmaru II-1780: sociedad colonial y sublevaciones populares, Retablo de Papel Ediciones, Lima, 1976, Gisbert, Teresa: El paraiso de los pájaros parlantes: la imagen del otro en la cultura andina, Plural Editores, La Paz, 2001. Valle de Siles, María Eugenia del: Historia de la rebelión de Tupac Catari, 1781-1782, Editorial Don Bosco, La Paz, Bolivia, 1990. Fisher, John Robert, Allan J. Kuethe and Anthony McFarlane: Reform and insurrection in Bourbon New Granada and Peru, Louisiana State University Press, Baton Rouge, 1990, Lewin, Boleslao: La rebelión de Túpac Amaru y los orígenes de la independencia de Hispanoamérica, SELA, Buenos Aires, 1967. 
con abrir nuevos campos temáticos (sobre todo los textos de Rosas Lauro sobre el embarazo y la maternindad y Sala i Vila sobre los catalanes en la administración virreynal), estos trabajos también contribuyen a los temas clásicos de los andes en el XVIII. En la actualidad, los estudios andinos o, mejor, la historia andina (un término cuestionable en sí mismo) se caracteriza por una saludable heterogeneidad de temáticas, metodologías e influencias teóricas. Al organizar este dossier, nos dimos cuenta que tres artículos no podrían (como tampoco hubiesen podido 5 u 8) representar fehacientemente recientes tendencias historiográficas ya que la inclinación mayor es justamente hacia la ampliación de temas y la búsqueda de nuevas perspectivas. ${ }^{2}$ Sin embargo, encontramos algunos intereses e inspiraciones en común en estos y otros trabajos recientes. Del mismo modo, las reformas borbónicas y las rebeliones mantienen su importancia a pesar de lo que a primera vista parece ser un alejamiento. En realidad, estos tres ensayos demuestran como los nuevos (y no tan nuevos) trabajos están enriqueciendo las bases interpretativas de la historia andina del siglo XVIII. Aquí resumiremos algunas de estas nuevas tendencias y sus posibles contribuciones.

Los tres ensayos demuestran los beneficios de ampliar el significado de conceptos como "la política" y el reformismo. Normalmente, los historiadores se han concentrado en las reformas administrativas, fiscales y militares a partir de Carlos III y, aunque suene reduccionista, los investigadores concuerdan que para España el gran objetivo de las reformas era aumentar los ingresos fiscales de las américas para enfrentar la competencia y constantes guerras con Inglaterra y Francia. La ocupación inglesa de La Habana en 1762 demostró, por ejemplo, la necesidad de mejorar los sistemas defensivos en las colonias. ${ }^{3}$ Sin embargo, el siglo XVIII también se caracteriza por otros cambios en las relaciones entre el estado y la sociedad civil. Siguiendo a Foucault, entre otros, algunos analistas resaltan la cambiante noción del cuerpo y la creación de nuevas formas de control social. Vemos un florecimiento de estudios sobre el cuerpo, la salud,

2 Dos libros que proponen (y logran) dar una visión general del siglo XVIII a través de artículos de especialistas captan esta búsqueda de nuevos temas y enfoques. Ver Tandeter, Enrique, Jorge Hidalgo Lehuede, eds.: Historia general de América Latina, Editorial Trotta/Ediciones UNESCO, Madrid, 1999, Garrido, Margarita, ed.: Historia de América Andina, Universidad Andina Simón Bolívar: Libresa, Quito, Ecuador, 1999. Para el Perú, O’Phelan, Scarlett: El Perú en el siglo XVIII: la Era Borbónica, Pontificia Universidad Catóica del Perú, Instituto Riva-Agüero, Lima, 1999.

3 Kuethe, Allan: "Conflicto internacional, orden colonial y militarización", en Tandeter, y Lehuede, eds.: Historia... 
la disciplina laboral, la familia y un buen número de otros temas pocas veces tocados en los análisis clásicos del reformismo borbónico. ${ }^{4}$ Estos estudios tienden a mantener el enfoque en el estado, como el promotor de las nuevas actitudes y políticas de la ilustración. Una de las características o tal vez contribuciones de estos estudios, entonces, es el replanteamiento del proceso reformista en sí mismo, llevando el análisis a zonas o temas pocos trabajados anteriormente. ${ }^{5}$

En la primera página de su erudito y ameno ensayo sobre la maternidad en el Perú a fines del siglo, Claudia Rosas Lauro reconoce la influencia de la historia de la medicina, el cuerpo y el género. La autora cita varias obras y corrientes basicamente europeas sobre la historia de la familia, la lectura, las esferas públicas y privadas, y la sociabilidad, pero también incorpora la considerable producción en estos campos sobre los Andes. Con esto queremos resaltar que no estamos frente a simples ecos tendenciosos de modas europeas - una corriente europea se reproduce en o sobre los Andes después de unos años y con una calidad inferior - sino frente a una saludable exploración de estos temas en los países andinos.

Pensamos (y esto es una opinion personal, cuestionada tal vez por muchos) que estas nuevas corrientes de ninguna manera reemplazan al estudio más tradicional de las reformas administrativas, fiscales, y militares. Más bien, insistimos en que pueden contribuir a una mayor comprensión de los cambios y continuidades con la implementación del absolutismo borbónico y complementar los avances anteriores. Género ya es una categoría absolutamente válida para comprender el siglo de la ilustración en los Andes pero de ninguna manera sustituye al cuestionamiento de los cambios radicales y no tan radicales en la administración del poder español. El agudo análisis que Rosas Lauro hace del Mercurio Peruano y otros periódicos prueba que los ilustrados peruanos tomaban

4 Twinam, Ann: Public Lives, Private Secrets: Gender, Honor, Sexuality, and Illegitimacy in Colonial Spanish America, Stanford University Press, Stanford, 1999. Premo, Bianca: Children of the Father King: Youth, Authority and Legal Minority in Colonial Lima, University of North Carolina, Chapel Hill, 2001. Warren, Adam: Piety and Danger: Popular Ritual, Epidemics, and Medical Reforms in Lima, Peru, 1750-1860, UC San Diego, San Diego, 2004. Viqueira Albán, Juan Pedro: Relajados o reprimidos?: Diversiones públicas y vida social en la Ciudad de México durante el Siglo de las Luces, Fondo de Cultura Económica, México, 1987.

5 Jacobsen, Nils y Cristóbal Aljovin, eds.: Political Culture in the Andes, Duke University Press, en prensa. También importantes son los trabajos de Pablo Macera. Entre ellos Macera, Pablo: Tres etapas en el desarrollo de la conciencia nacional, Editorial "FANAL", Lima, 1955. 
muy en serio las nuevas formas de entender y controlar al cuerpo, sobre todo el feminino. ${ }^{6}$

Estos ensayos también pretenden ampliar los parámetros geográficos y cronológicos de los estudios andinos dieciochescos. En primer lugar, el ensayo de Nuria Sala i Vila contribuye al clamor de que "la política española" no se puede reducir a Madrid y su corte. Su estudio del Virrey Castelldosrius subraya la importancia de los catalanes en el Perú, demostrando la riqueza de una perspectiva no tan castellana y la existencia de fuentes importantes en Cataluña. En un libro polémico, sugerente, y algo extremo, Henry Kamen pone en cuestión el exagerado énfasis en Madrid y Castilla para comprender el imperio español. En Imperio, La forja de España como potencia mundial, Kamen plantea que "estamos habituados a la idea de que España creó su imperio, pero es más útil especular con la idea de que el imperio creó España”, resaltando el papel de catalanes, genoveses, holandeses, africanos, mayas, aztecas, incas, etc. en la expansión española en los siglos XVI al XVIII. El libro ha sido criticado por algunas exageraciones - subestima, por ejemplo, el renacimiento español- y por algunos autores castellanos algo defensivos que cuestionan sus objetivos y originalidad. ${ }^{7} \mathrm{Al}$ levantar tanto polvo, el libro claramente ha tocado un nervio y esperamos que más allá de la polémica, avance el debate ya en curso sobre el significado de "España" y sus territorios europeos y ultramarinos. El artículo de Sala i Vila confirma el argumento general de Kamen de que para comprender el imperio español es necesario mirar hacia sus "márgenes".

Con erudición y empeño, Sala i Vila ilumina la complejidad de las redes políticas en Cataluña durante y después de la Guerra de Sucesión (1700-1713) a través de la examinación de la carrera de Castelldosrius, virrey del Peru de 1707 a 1710. No es una mera reivindicación, como pue-

6 Entre otros trabajos, ver Mannarelli, María Emma: Pecados Públicos. La ilegitimidad en Lima, siglo XVII, Lima, Flora Tristan, 1993; van Deusen, Nancy E.: Between the Sacred and the Wordly: The Institutional and Cultural Practice of Recogimiento in Colonial Lima, Stanford University Press, Stanford, 2001, Rosas Lauro, Claudia: "Jaque a la Dama: La imagen de la mujer en la prensa limeña de fines del siglo XVIII", Zegarra, Mujeres y género en la historia del Perú, CENDOC-Mujer, Lima, 1999; Bridikhina, Eugenia: Sin temor a Dios, ni a la justicia real: control social en Charcas a fines del siglo XVIII, Universidad Mayor de San Andrés, La Paz, 2000.

7 Kamen, Henry: Imperio. La forja de España como potencia mundial, Punto de Lectura, Madrid, 2004., pág. 15. Para una mesurada crítica, ver Carlos Martínez Shaw, "El don de la oportunidad," Babelia (El País), Madrid, 29 de Marzo, 2003. Para un resumen de las críticas mas fuertes, ver el artículo del mismo Kamen "Why My Book About Spain Upset the Spanish", The Guardian, London, 17 de Marzo, 2003 
den ser los trabajos "regionales" cuyo motivo principal es estudiar una zona "olvidada", sino un refrescante replanteamiento de la cultura política de comienzos del siglo XVIII. ${ }^{8}$

Su ensayo no sólo amplía las fronteras geográficas sino también las temporales. La mayoría de los estudios sobre el siglo XVIII en los Andes se concentran en las ultimas décadas, lo que en gran parte se explica por ser este el momento de las reformas de Carlos III y las rebeliones de Tupac Amaru y Tupac Katari. El trabajo de Sala i Vila se une a un creciente interés en la primera mitad del siglo por parte de autores como Alfredo Moreno Cebrián, importante promotor de ello, y Adrian Pearce. ${ }^{9}$ Con estos y otros trabajos, podemos comprender "el largo siglo XVIII", sobre todo en cuanto a los cambiantes motivos y métodos del absolutismo borbónico. Esa revisión cronológica —el análisis de la relación entre las "proto-reformas" de Felipe V y Fernando VI y las de Carlos III y de las normas e inquietudes políticas en el virreinato a través de todo el siglo- es una tarea pendiente pero trabajos como el de Sala i Vila nos permiten comenzarlo.

También nos encontramos frente a una constante reinterpretación de las rebeliones de la década de 1780. En el artículo aquí publicado y su importante y reciente libro, Sergio Serulnikov logra unir dos tendencias que si bien parecen contradictorias, él y otros autores han mostrado que son mutuamente necesarias: combinar la microhistoria del poder local con una visión más amplia, regional y hasta transatlántica, y, por tanto, comparativa. ${ }^{10}$ En su fino análisis de la zona nor-potosina, Serulnikov demuestra que es necesario examinar con mucho cuidado los cambios tanto en la función como en la legitimidad de los caciques. En su ensayo, el poder local —la

8 Justamente la historiografía de España en el siglo XVIII se caracteriza por el florecimiento de estudios regionales. Para un buen resumen, ver Fernández, Roberto: La España Moderna: El Siglo XVIII, historia 16, Madrid, 1993. Kamen también reconoce su importancia en su propio estudio.

9 Pearce, Adrian J.: "The Peruvian Population Census of 1725-1740", Latin American Research Review, 36-3, 2001, págs. 69-104, y Early Bourbon Government in the Viceroyalty of Peru, 1700-1759, University of Liverpool, Liverpool, 1998. Moreno Cebrián, Alfredo: El virreinato del Marqués de Castelfuerte, 1724-1736: el primer intento borbónico por reformar el Perú, Editorial Catriel, Madrid, España, 2000, y Superunda, Conde de: Relación de gobierno, Perú (1745-1761), CSIC, Madrid, 1983.

10 Serulnikov, Sergio: Subverting Colonial Authority: Challenges to Spanish Rule in the Eighteenth-Century Southern Andes, Duke University Press, Durham, 2003. Otros estudios incluyen Stavig, Ward: The world of Tupac Amaru: conflict, community, and identity in colonial Peru, University of Nebraska Press, Lincoln, 1999. Thomson, Sinclair: We alone will rule: native Andean politics in the age of insurgency, University of Wisconsin Press, Madison, 2002. Para el libro que influyó a estos recientes estudios, ver Stern, Steve, ed.: Resistencia, rebelión y conciencia campesina en los andes, siglos XVIII al XX, Instituto de Estudios Peruanos, Lima, 1990. 
base de los conflictos que estallan en las rebeliones - varía y cambia a través del tiempo y el espacio. Los conflictos de una comunidad no pueden ser impuestos como modelo básico para otros: es indispensable hacer una verdadera comparación. Recientes estudios analizan de manera cada vez más focalizada las relaciones o alineaciones entre los individuos o representantes como caciques (que Serulnikov prueba es un término complejo, una institución dinámica de frecuente cambio), alcaldes, corregidores, curas e hilacatas y las instituciones como el ayllu, las cofradías, los cabildos indígenas y las comunidades. ${ }^{11}$ Para entender las tensiones que ayudaron a fomentar las rebeliones masivas el autor indica la necesidad de no tomar estas relaciones o estos puestos (sobre todo el cacicazgo) como algo fijo (o esencial) en el tiempo y adentrarse en las relaciones locales de poder. A la vez - y aquí vemos su gran contribución, un verdadero reto para los historiadores-Serulnikov presenta una visión comparativa para comprender las importantes diferencias regionales en la época de la gran rebelión. Interpretaciones que enfatizan un solo factor (la deslegitimad de los caciques o la presión fiscal) o que aplican o imponen sus hallazgos relativos a una localidad sobre otras tendrán que afrontar este modelo.

Los ensayos aquí presentados no sólo contribuyen a un replanteamiento del reformismo ilustrado y un refinamiento del análisis de los levantamientos sociales. En su conjunto, los tres textos demuestran también un acertado interés en la historia cultural. A pesar de sus marcadas diferencias temáticas, todos prestan atención al flujo de ideas y de alguna manera a los intermediarios culturales. ${ }^{12}$ Entre los temas tratados en los tres ensayos que son sujetos de debates historiográficos importantes se encuentran la prensa (Rosas Lauro), la cultura cortesana (Sala i Vila), y la noción de la legitimidad política (Serulnikov). ${ }^{13}$ No queremos decir que los ensayos pretenden

11 La influencia de los trabajos de Tristan Platt y Thierry Saignes en los estudios del XVIII es notable. Entre sus trabajos, Platt, Tristan: Estado boliviano y ayllu andino: tierra y tributo en el norte de Potosí, Instituto de Estudios Peruanos, Lima, 1982. Saignes, Thierry and C. Salazar-Soler: Borrachera y memoria: la experiencia de lo sagrado en los Andes, Hisbol; Instituto Francés de Estudios Andinos, La Paz, Bolivia. Lima, Perú, 1993.

12 Ares Queija, Berta and Serge Gruzinski: Entre dos mundos: fronteras culturales y agentes mediadores, Escuela de Estudios Hispano-Americanos, Consejo Superior de Investigaciones Científicas, Sevilla, 1997.

13 Sobre la prensa, trabajos destacados incluyen Clément, Jean-Pierre: El Mercurio Peruano, 1790-1795, Vervuert, Iberoamericana, Frankfurt, Madrid, 1997, Martínez Riaza, Ascensión: La prensa doctrinal en la independencia del Perú, 1811-1824, Ediciones Cultura Hispanica, ICI, Madrid, 1985. Glave, Luis Miguel, ed.: Del pliego al periódico: Prensa, espacios públicos y construcción nacional en Iberoamerica, Fundacion MAPFRE Tavera, Madrid, 2003. Sobre la sociabilidad y la identidad, entre 
tratar de manera diletante temas de moda, sino que en su conjunto toman en serio el discurso y las representaciones del poder, caminos imprescindibles para mejorar el conocimiento de los Andes en el siglo XVIII.

\section{Los ensayos}

Nuria Sala i Vila analiza al poco estudiado Virrey Castelldosrius (1651-1710), nombrado en plena Guerra de Sucesión. Como adelantamos, el estudio es mucho más que una reivindicación del papel de los catalanes en el Perú colonial. Sus referencias indican los beneficios de apartarse de fuentes tradicionales e indagar en los archivos menos trabajados para las Américas en el siglo XVIII, como los de Cataluña. Además, demuestra las ventajas e importancia de estudiar esta época relativamente soslayada.

Manuel de Oms de Santapau Olim Sentmenat i de Lanuza, cuyo nombre indica su nobleza, formó parte de una minoría catalana que apoyó a los borbones en la Guerra de Sucesión. Buscó ir al Perú para recuperar su patrimonio, seriamente dañado por la ocupación austriacista. Su espera y viaje de España a Lima se prolongó por varios años debido a la guerra y, en realidad, duró igual o más que su tiempo como virrey (1707-1710). Lo que Sala i Vila ilumina es la vida de corte del afrancesado Castelldosrius. Para algunos, es un virrey abiertamente corrupto que entabla negocios turbios con comerciantes franceses y una lista larguísima de colaboradores (incluida aquí), muchos de ellos parte de su séquito. Ganó enemigos rápidamente en Lima y no escondió su disgusto por la ciudad. Por otro lado, renueva la vida cortesana en la capital al introducir o promocionar nuevas formas de literatura, teatro, celebraciones y sociabilidad en general. No se puede, por lo tanto, reducir el mandato de Castelldosrius a un breve y desafortunado momento de negocios cuestionables, ya que cambió la vida cortesana y hasta social de Lima. La autora analiza los "comportamientos colectivos de amplios sectores" catalanes y destaca sus

\footnotetext{
muchos trabajos, Herzog, Tamar: Defining nations: immigrants and citizens in early modern Spain and Spanish America, Yale University Press, New Haven, 2003. Guerra, Francois-Xavier: Las revoluciones hispánicas: independencias americanas y liberalismo español, Editorial Complutense, Madrid, 1995, Guerra, Francois-Xavier and Annick Lempériére: Los espacios públicos en Iberoamérica: ambiguedades y problemas, siglos XVIII y XIX, Centro Francés de Estudios Mexicanos y Centroamericanos: Fondo de Cultura Económica, México, D.F., 1998.
} 
circuitos, dando importantes pautas sobre los cambios y las continuidades ocurridas en Lima durante la transición de los habsburgos a los borbones. ${ }^{14}$

Claudia Rosas Lauro capta las múltiples influencias y motivos que se combinaron para cambiar drásticamente la visión de la madre y la maternidad en el Perú en el siglo XVIII. De manera correcta, la autora no resume estas influencias de manera simplista bajo "la ilustración", sino que permite ver las diferentes corrientes y sus relaciones entre sí. Estas incluyen la secularización, el surgimiento de nuevas ideas científicas y el crecimiento del poderío y la autonomía de los médicos como especialistas encargados de supervisar el cuerpo femenino. El análisis se mueve desde el embarazo - la discusión sobre la "protección" del feto es destacable - al parto y desde ahí, al cuidado del niño. Demuestra que los debates y los cambios sobre la reproducción formaron parte de las reformas dieciochescas y confirma la categoría de género (y/o familia y cuerpo) como elemento fundamental de estos cambios.

A la vez que la autora enriquece su estudio con una aguda incorporación de debates sobre la mujer, la familia y la ciencia, su estudio se adentra en la historia social e intelectual de Lima en la segunda mitad del siglo. Se basa en una lectura cuidadosa de los periódicos de la época para desglosar los distintos discursos sobre la madre. Destaca el desarrollo de la idea de la necesidad de educar (o controlar) a la madre para que cumpla con su misión de "configurar a la familia", característica clave de la naciente mentalidad burguesa. El artículo interesará tanto a los estudiosos de Lima en el siglo XVIII como a los del género.

El ensayo de Sergio Serulnikov es un notable ejemplo de etnohistoria que dialoga con y contribuye a debates sobre el poder en los Andes y el siglo de las revoluciones. Es decir, vincula su cuidadoso análisis de las comunidades nor-potosinas con las rebeliones pan-Andinas y sus repercusiones. Demuestra también las diferencias bastante drásticas entre distintos repartimientos en cuanto a sus estructuras de poder y etnicidad. En la primera sección, bosqueja esta complejidad de la "estructuración étnica" en

14 Sobre la vida de Lima en los siglos XVII y XVIII (entre otros), los trabajos de Guillermo Lohmann Villena son imprescindibles. Entre ellos Lohmann Villena, Guillermo: Las relaciones de los virreyes del Perú, Escuela de Estudios Hispano-Americanos, Sevilla, 1959; El arte dramático en Lima durante el virreinato, CSIC, Escuela de Estudios Hispano-Americanos, Madrid, 1945; Los ministros de la audiencia de Lima en el reinado de los Borbones (1700-1821). Esquema de un estudio sobre un núcleo dirigente, Escuela de Estudios Hispano-Americanos, Sevilla, 1974.Para nuevas perspectivas y una mina de información sobre la aristocracía limeña, Rizo-Patrón Boyle, Paul: Linaje, Dote, y Poder: La nobleza de Lima de 1700 a 1850, Pontificia Universidad Católica, Lima, 2000. 
Chayanta, destacando que más allá de las diferentes conformaciones de la representación dentro de los distintos repartimientos, los caciques y otros jefes indígenas mantenían un papel importante tanto en las relaciones del ayllu con el mundo exterior como con los actos simbólicos (el mundo ritual) internos. Sin embargo, los caciques hereditarios o de linaje no mantenían la legitimidad que sí tenían en Bajo Perú, y así la institución perdía sus "principios nobiliarios". Más bien, surgieron criterios representativos y hasta igualitarios que sin poner en duda la institución del caciquazgo, servían para cuestionar a las elites rurales. Seguir esta transición y el enfrentamiento de nociones sobre el papel del cacique abre nuevas pistas para comprender las grandes rebeliones y la transición de colonia a república. Serulnikov examina estos procesos desde una perspectiva comparativa, dando importantes pistas y retando a otros historiadores.

\section{Lo que falta}

Es imposible que tres ensayos cubran los Andes en el siglo XVIII.” En ningún momento pretendemos proporcionar una visión panorámica o una síntesis comparativa; ni podemos pretender que estos tres excelentes ensayos retraten todas las nuevas (y no tan nuevas) tendencias y corrientes. Contamos con una importante síntesis comparativa para el siglo XIX en el libro de Brooke Larson; para el siglo XVIII tendremos que esperar. ${ }^{15}$ Para terminar, nos gustaría mencionar algunos de los vacíos y tendencias.

Aunque insistimos en la necesidad de ampliar fronteras geográficas, no están presentes aquí la amazonía ni los territorios que llegarían a constitur Chile, Ecuador, y Colombia. Pasando al otro lado del Atlántico, aunque el ensayo de Sala i Vila demuestra las ventajas de una perspectiva geográfica más amplia, no queremos decir que los estudios en y sobre el poder en Madrid se han agotado. Al contrario, la investigación de los Andes en el XVIII puede beneficiarse de un replanteamiento de las políticas y los procesos culturales españoles. ${ }^{16}$ Los interesados — por ejemplo, en las refor-

15 Larson, Brooke: Indígenas, élites y estado en la formación de las repúblicas andinas, IEP, Pontificia Universidad Católica del Perú, Lima, 2002.

16 Dos ejemplos de importantes artículos que se mueven entre los andes y Madrid son Moreno Cebrián, Alfredo: "El Regalismo Borbónico frente al Poder Vaticano: Acerca del Estado de la Iglesia en el Perú Durante el Primer Tercio del Siglo XVIII", Revista de Indias, LXIII-227, 2003, págs. 223274. Víctor Peralta Ruíz: "Un indiano en la Corte de Madrid. Dionisio de Alsedo y Herrera y el Memorial informativo del Consulado de Lima de 1725", Histórica, XXVII, 2, 2003, en prensa. 
mas urbanas y el control social- pueden aprender mucho de los estudios de ellos en España misma. ${ }^{17}$

Los estudios del arte plástico ya no constituyen un campo algo alejado de la historia social. Más bien los trabajos de Juan Carlos Estenssoro, Luis Wuffarden, Ramón Mujica y Teresa Gisbert, entre otros, constituyen hitos importantes en los debates sobre "raza" y las categorías sociales. ${ }^{18}$ Estimo que sus aproximaciones y los estudios de género han sido los aportes más importantes en la última década sobre estos temas. También está ausente la historia económica, campo magníficamente trabajado por el recordado Enrique Tandeter. ${ }^{19}$ Podría dar una lista larga de importantes renovaciones en el estudio del siglo XVIII y otra de vacíos igualmente destacados. Sin embargo, confiamos que estos tres textos son un valioso aporte y que provocarán un mayor debate y tal vez nuevos estudios.

Para terminar, tal vez valga la pena notar la "multinacionalidad" de los estudios andinos. Entre los autores se encuentran un argentino que investiga en archivos bolivianos y enseña en Estados Unidos, una peruana que está terminando un doctorado en Italia, y una catalana con corazón ayacuchano. El dossier mismo surgió como producto de conversaciones entre el argentino Ricardo González Leandri y el estadounidense que escribe, mientras los dos vivíamos en Sevilla. El hecho de que la historia andina se

17 Innovadores estudios sobre Lima incluyen Cosamalón Aguilar, Jesús: Indios detrás de la muralla, Pontificia Universidad Católica del Perú, Lima, 1999. Lossio, Jorge: Acequias y gallinazos: salud ambiental en Lima del siglo XIX, IEP Instituto de Estudios Peruanos, Lima, Perú, 2003. Ramón Joffré, Gabriel: La muralla y los callejones. Intervención urbana y proyecto político en Lima durante la segunda mitad del siglo XIX, SIDEA-PromPerú, 1999. Pérez-Mallaina Bueno, Pablo Emilio: Retrato de una ciudad en crisis: La sociedad limeña ante el movimiento sísmico de 1746, CSIC, Escuela de Estudios Hispano-Americanos/Instituto Riva-Agüero, Sevilla, 2001.Libro fundamental es Alberto Flores Galindo: Aristocracia y plebe. Lima, 1760-1830, Mosca Azul, Lima, 1984.

18 Wuffarden, Luis Eduardo: "La ciudad y sus emblemas: imágenes del criollismo en el virreinato del Perú", en Sociedad estatal para la conmemoración de los centenarios de Felipe II y Carlos V", Los Siglos de Oro en los Virreinatos de América 1550-1700, Madrid, 2000, págs. 59-76 y "Los lienzos del virrey Amat y la pintura limeña del siglo XVIII", en Majluf, Natalia, editora, Los cuadros de mestizaje del virrey Amat. La representación iconográfica en el Perú colonial, Museo de arte, Lima, 2000, págs. 49-65. Estenssoro Fuchs, Juan Carlos: "Los colores de la plebe: razón y mestizaje en el Perú colonial", en Majluf, Los cuadros..., y "Modernismo, estética, música y fiesta: elites y cambio de actitud frente a la cultura popular", Perú 1750-1850, en Urbano, Henrique, Tradición y modernidad en los Andes, Centro Bartolomé de las Casas, Cusco, 1992, págs. 181-195. Gisbert, Teresa: El paraíso de los pájaros parlantes: la imagen del otro en la cultura andina, Plural Editores, La Paz, 2001. Mujica Pinilla, Ramón: Rosa limensis: Mística, política e iconografía en torno a la patrona de América, IFEA, Fondo de Cultura económica, Banco Central de la Reserva del Perú, Lima, 2001.

19 Entre su amplia bibliografía, en español, francés, e inglés, una obra particularmente importante para el tema de este dossier es Tandeter, Enrique: Coacción y mercado: la minería de la plata en el Potosí colonial, 1692-1826, Centro "Bartolomé de Las Casas", Cusco, 1992. 
produce y se escribe en los paises andinos pero también en Europa y Estados Unidos refleja varios fenónemos. Por un lado, es indudable que los historiadores andinos tienen dificultades para investigar y publicar (y sobrevivir) en sus países de origen y muchos han salido al exterior. Por otro lado - y en parte debido a esta emigración — los estudios andinos tienen la calidad y el prestigio para constituirse en importantes referencias más allá de América del Sur. Esperamos que estos textos constituyan otra contribución y que honren la memoria de Enrique Tandeter. 